\title{
Using the instantaneous power of a free acceleration test for squirrel-cage motor parameters estimation
}

\author{
Hengameh Kojooyan-Jafari, Lluis Monjo, Student Member, IEEE, Felipe Córcoles, Joaquin Pedra, \\ Member, IEEE
}

\begin{abstract}
A new parameters determination method for squirrel-cage induction motors is presented. As a main contribution, the method uses the instantaneous electrical power and the mechanical speed measured in a free acceleration test to estimate the double-cage model parameters. The parameters are estimated from the machine impedance calculated at several points: (1) at speed points where the double-cage effect is significant, i.e., between the zero speed point and the maximum torque point, the machine impedance is evaluated by the instantaneous power method and (2) at speed points where the doublecage effect is not significant, i.e., between the maximum torque point and synchronism, the machine impedance is evaluated by a dynamic model based linear least square method. The proposed method has been applied to obtain the parameters of three motors tested in the laboratory. To check the method accuracy, the steady-state torque- and current-slip curves predicted by the estimated parameters are successfully compared with those measured in the laboratory.
\end{abstract}

Index Terms-Parameters estimation, double-cage model, starting transient measurements.

\section{INTRODUCTION}

$\mathrm{T}$ HE accuracy of the motor parameters in simulations is crucial for performance prediction during a system disturbance, during the motor starting or when advanced control techniques are used. An important review of induction motor estimation techniques can be found in [1].

The main parameter estimation techniques from experimental measurements are based on:

- Steady-state measurements [2]-[9].

- Variable frequency measurements [10]-[13].

- Transient measurements [14]-[26].

The simplest and most common parameter estimation procedures are based on steady-state measurements. Ref. [11] gives a brief introduction to these techniques based on dc, noload and short-circuit tests. Moreover, two standards for this kind of procedures [2][3]. IEEE Std-112 [2] and IEC Rotating Electrical machines-Part 28 [3] describe the most usual parameter estimation methods, which are based on short-circuit and no-load tests. Finally, advances in steady-state parameter estimation via linear regression can be found in [4]. Regarding the double-cage model, the minimum number of parameters that characterize the double-cage model is studied in [6], whereas parameter estimation procedures based on steadystate data are presented in [7][8]. The Matlab/Simulink function "Power Asynchronous Machine Params" [9] is based on the above works.

Methods based on variable frequency tests can be divided into two types: those using sources with tunable voltage and frequency [10][11], and those using sources with PWM voltage waveforms [12][13].

Finally, methods based on transient measurements can be classified into four categories:

- Kalman filter methods [14]-[16].

- Linear least square methods [17]-[21].

- Non-linear least square methods [22]-[25].

- Instantaneous rms methods [26]-[27].

The extended Kalman filter allows optimal state estimation of non-linear systems in the presence of noise. Linear least square (LLSQ) methods manipulate electric machine differential equations to eliminate the non-measurable rotor magnitudes (rotor currents and fluxes). In non-linear least square methods, an error function is calculated from measured and simulated currents. These techniques have a large computational burden because each error function evaluation requires a transient simulation. The minimization of this error function leads to different parameters estimation approaches. Other methodologies use instantaneous rms current measurements as steady-state values.

All of these methodologies are largely applied to the singlecage model parameters estimation (Fig. 1a). Usually, this model can be adequate for some small squirrel-cage motors or for wound rotor motors, but a double-cage model (Fig. 1b) can be necessary to justify the experimental starting torque and current measurements in small, medium and large motors [28]. Despite the double-cage model parameters estimation is not a new topic in the literature, the estimation methods based on transient measurements have been only applied in the past to the single-cage model. Only [29] mentions the double-cage model parameters estimation problem based on transient data, but does not provide a clear methodology to perform the estimation.

The main objective of this paper is to present a clear novel methodology for the double-cage model parameters estimation using the instantaneous voltages, currents and speed measured in a free acceleration test.
This research work has been supported by grant ENE2009-10274.

Hengameh Kojooyan-Jafari, Ll. Monjo, F. Córcoles and J. Pedra are with the Department of Electrical Engineering, ETSEIB-UPC, Av. Diagonal 647, 08028 Barcelona, Spain (e-mails: kojooyan@iiau.ac.ir, lluis.monjo@upc.edu, corcoles@ee.upc.es, pedra@ee.upc.es). 


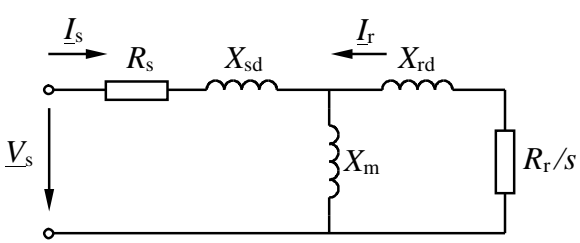

(a)

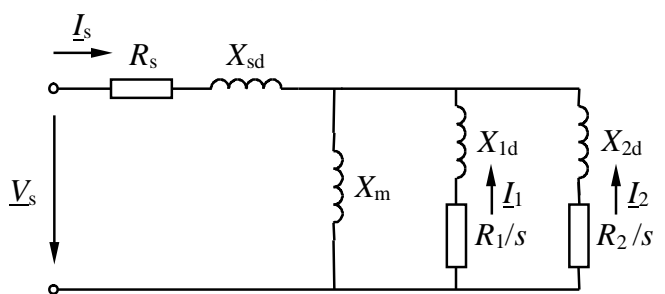

(b)

Fig. 1. Steady-state star equivalent circuit for the (a) single-cage and (b) double-cage models of the squirrel-cage induction motor.

\section{INDUCTION MOTOR MODEL}

\section{A. Steady-State Modeling}

The circles in Fig. 2 represent the steady-state torque and current of two medium-sized ABB motors measured by the manufacturer (the catalogue data are summarized in Table I). Table II contains the single- and double-cage model parameters estimated from these steady-state measurements [7]. The curves predicted by both models are also plotted in Fig. 2. As expected, the double-cage model (solid line) exhibits a good agreement between measurements and predictions whereas the single-cage model (dotted line) only provides accurate results between the maximum torque point and the synchronous speed. Fig. 2 clearly shows that both motors should be
TABLE I

Catalogue Data of Tested SouirREL-CAGE Induction Motors

\begin{tabular}{ccccccccccc}
\hline \hline Motor & $\begin{array}{c}P_{\mathrm{N}} \\
(\mathrm{kW})\end{array}$ & $\begin{array}{c}U_{\mathrm{N}} \\
(\mathrm{V})\end{array}$ & $\begin{array}{c}f_{\mathrm{N}} \\
(\mathrm{Hz})\end{array}$ & $P F_{\mathrm{N}}$ & $\begin{array}{c}\omega_{\mathrm{N}} \\
(\mathrm{r} / \mathrm{min})\end{array}$ & $\begin{array}{c}\eta_{\mathrm{N}} \\
(\%)\end{array}$ & $\begin{array}{c}T_{\mathrm{MAX}} \\
T_{\mathrm{N}}\end{array}$ & $\begin{array}{c}T_{\mathrm{ST}} \\
/ T_{\mathrm{N}}\end{array}$ & $\begin{array}{c}I_{\mathrm{ST}} \\
/ I_{\mathrm{N}}\end{array}$ & $\begin{array}{c}J \\
\left(\mathrm{~kg} \cdot \mathrm{m}^{2}\right)\end{array}$ \\
\hline$\# 1$ & 75 & 400 & 50 & 0.86 & 1480 & 93.6 & 4.7 & 3.8 & 5.9 & 4.9 \\
$\# 2$ & 37 & 400 & 50 & 0.83 & 985 & 92.3 & 4.0 & 4.6 & 5.8 & 3.1 \\
$\# 3$ & 1.5 & 400 & 50 & 0.69 & 940 & 79.1 & 2.3 & 1.7 & 3.9 & $0.115^{*}$ \\
$\# 4$ & 2.2 & 400 & 50 & 0.80 & 1430 & 86.0 & 2.6 & 2.3 & 6.3 & $0.200^{*}$ \\
$\# 5$ & 2.2 & 400 & 50 & 0.75 & 950 & 86.7 & 3.4 & 3.1 & 7.1 & $0.193^{*}$
\end{tabular}

* These values include the inertia of the DC machine connected to the shaft of the squirrel-cage induction motor.

represented with a double-cage model [28]. The figure also contains with discontinuous lines the predicted curves with the proposed method in this paper: a double-cage model from estimated a free acceleration test. We will return to these curves in Subsection III.E.

\section{B. Transient Modeling}

The dynamic equations of the single-cage induction motor model in the synchronous reference frame are

$$
\begin{gathered}
v_{\mathrm{s}}=\left(R_{\mathrm{s}}+L_{\mathrm{s}}(p+\mathrm{j} \omega)\right) i_{\mathrm{s}}+M(p+\mathrm{j} \omega) i_{\mathrm{r}} \\
0=M(p+\mathrm{j} s \omega) i_{\mathrm{s}}+\left(R_{\mathrm{r}}+L_{\mathrm{r}}(p+\mathrm{j} s \omega)\right) i_{\mathrm{r}} \\
T(t)=2 \wp M \operatorname{Im}\left(i_{\mathrm{s}} i_{\mathrm{r}}^{*}\right) \quad, \quad s=\left(\omega-\wp \omega_{\mathrm{m}}\right) / \omega,
\end{gathered}
$$

where $\wp$ is the number of pole pairs, $\omega$ is the synchronous speed, $\omega_{\mathrm{m}}$ is the mechanical speed, $s$ is the slip. The self and mutual inductances are calculated as:

$M=X_{\mathrm{m}} / \omega ; L_{\mathrm{s}}=\left(X_{\mathrm{sd}}+X_{\mathrm{m}}\right) / \omega ; L_{\mathrm{r}}=\left(X_{\mathrm{rd}}+X_{\mathrm{m}}\right) / \omega$.

The dynamic equations of the double-cage induction motor

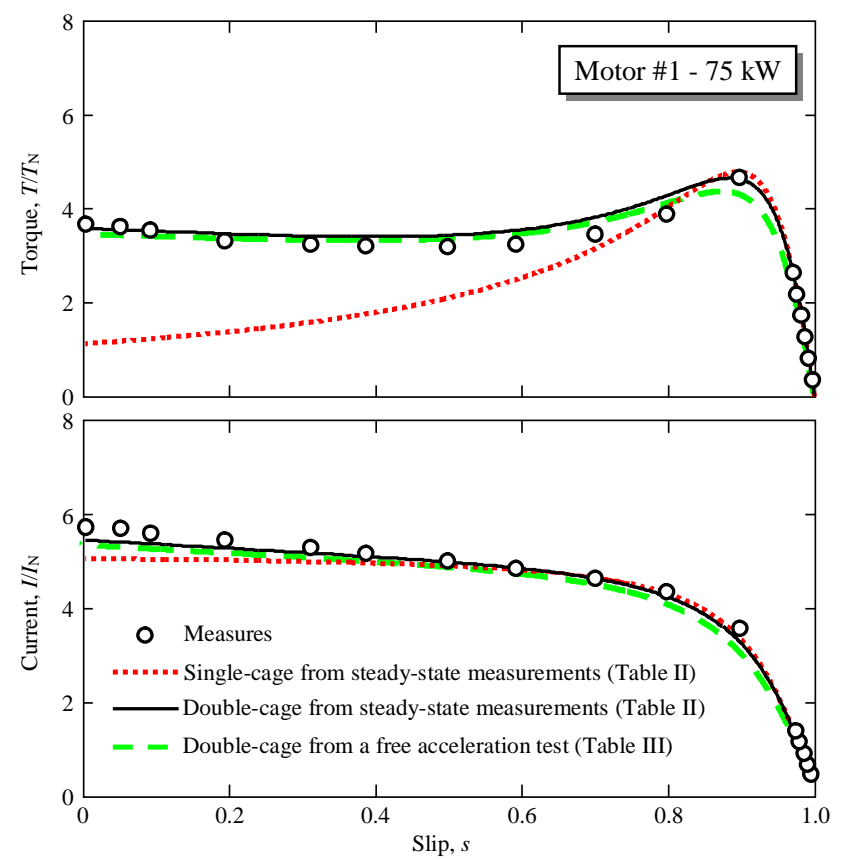

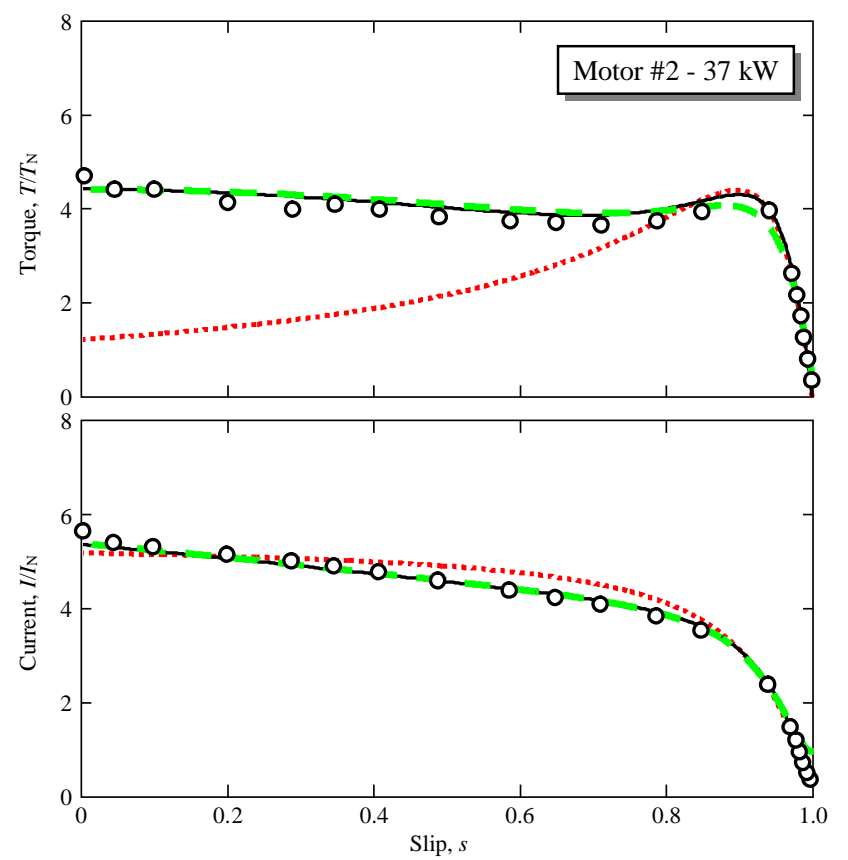

Fig. 2. Measured (marked with circles) and predicted torque- and current-slip curves for motors \#1 and \#2. Models used for torque and current prediction: singlecage model from steady-state measurements (dotted line), double-cage model from steady-state measurements (solid line) and double-cage model from a free acceleration test (discontinuous line). 
TABLE II

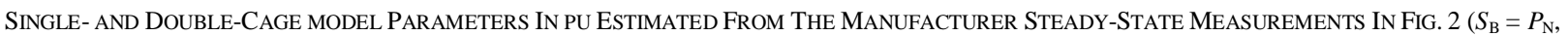
$\left.U_{\mathrm{B}}=U_{\mathrm{N}}, Z_{\mathrm{B}}=U_{\mathrm{B}}{ }^{2} / S_{\mathrm{B}}\right)$

\begin{tabular}{c|cccc|cccccc}
\hline \hline & \multicolumn{4}{|c|}{ Single-cage model } & \multicolumn{5}{c}{ Double-cage model } \\
\hline Motor & $r_{\mathrm{s}}$ & $x_{\mathrm{sd}}=x_{\mathrm{rd}}$ & $x_{\mathrm{m}}$ & $r_{\mathrm{r}}$ & $r_{\mathrm{s}}$ & $x_{\mathrm{sd}}=x_{2 \mathrm{~d}}$ & $x_{\mathrm{m}}$ & $r_{1}$ & $x_{1 \mathrm{~d}}$ & $r_{2}$ \\
\hline$\# 1$ & 0.0280 & 0.0810 & 1.5156 & 0.0169 & 0.0544 & 0.0474 & 1.9051 & 0.0182 & 0.1108 & 0.1964 \\
\hline$\# 2$ & 0.0716 & 0.0633 & 2.1839 & 0.0150 & 0.0647 & 0.0379 & 1.9587 & 0.0166 & 0.1416 & 0.1092 \\
\hline \hline
\end{tabular}

model in the synchronous reference frame are

$$
\begin{aligned}
& v_{\mathrm{s}}=\left(R_{\mathrm{s}}+L_{\mathrm{s}}(p+\mathrm{j} \omega)\right) i_{\mathrm{s}}+M(p+\mathrm{j} \omega) i_{1}+M(p+\mathrm{j} \omega) i_{2} \\
& 0=M(p+\mathrm{j} s \omega) i_{\mathrm{s}}+\left(R_{1}+L_{1}(p+\mathrm{j} s \omega)\right) i_{1}+M(p+\mathrm{j} s \omega) i_{2} \\
& 0=M(p+\mathrm{j} s \omega) i_{\mathrm{s}}+M(p+\mathrm{j} s \omega) i_{1}+\left(R_{2}+L_{2}(p+\mathrm{j} s \omega)\right) i_{2} \\
& T(t)=2 \cdot \wp \cdot M \cdot \operatorname{Im}\left(i_{\mathrm{s}}\left(i_{1}^{*}+i_{2}^{*}\right)\right) \quad, \quad s=\left(\omega-\wp \omega_{\mathrm{m}}\right) / \omega,
\end{aligned}
$$

where the self and mutual inductances are calculated as:

$$
\begin{gathered}
M=X_{\mathrm{m}} / \omega ; \quad L_{\mathrm{s}}=\left(X_{\mathrm{sd}}+X_{\mathrm{m}}\right) / \omega \\
L_{1}=\left(X_{1 \mathrm{~d}}+X_{\mathrm{m}}\right) / \omega \quad ; \quad L_{2}=\left(X_{2 \mathrm{~d}}+X_{\mathrm{m}}\right) / \omega .
\end{gathered}
$$

The relation between the above complex variables and the Park variables (dq components) is

$$
x_{\mathrm{s}}=\frac{x_{\mathrm{sd}}+\mathrm{j} x_{\mathrm{sq}}}{\sqrt{2}} ; x=v, i .
$$

The instantaneous stator currents and voltages can be transformed into the Park variables according to next rela-
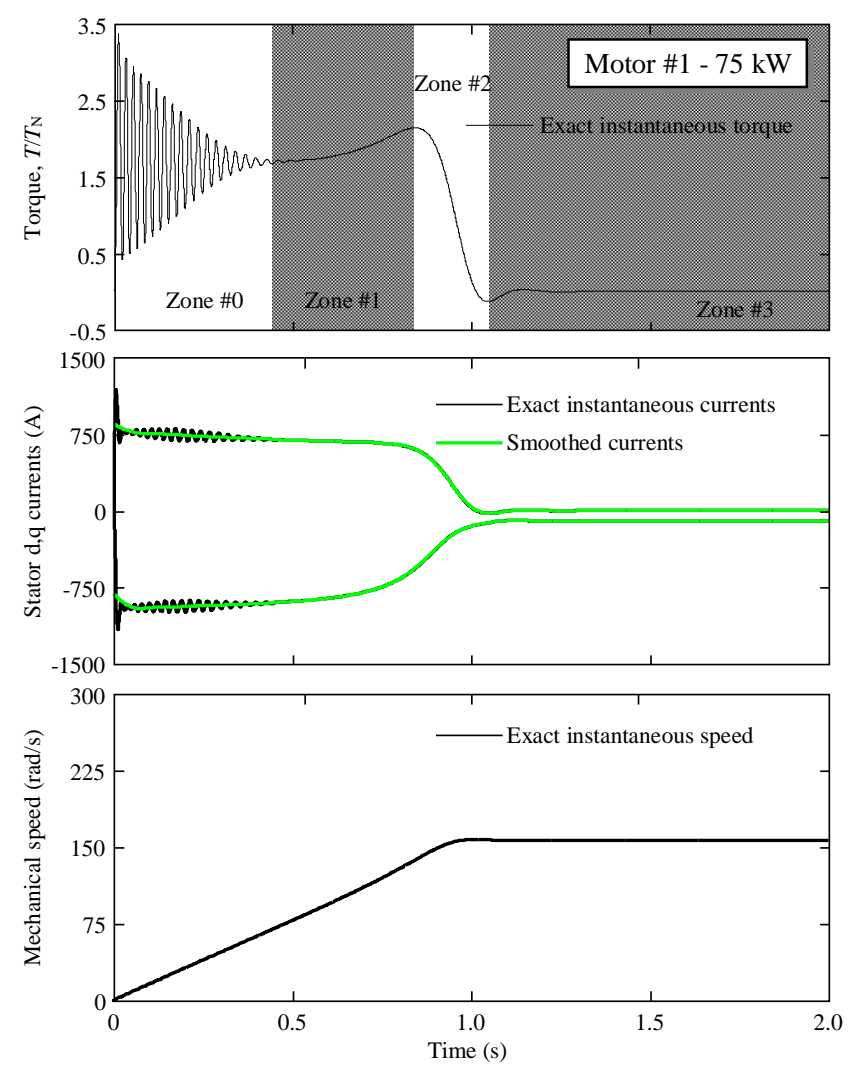

Fig. 3. Exact (calculated by simulation) instantaneous torque, direct and quadrature stator currents, and mechanical speed in a free acceleration test on motors \#1 and \#2. tions:

$$
\begin{aligned}
& x_{\mathrm{sd}}=\sqrt{\frac{2}{3}}\left\{x_{\mathrm{sa}} \cos \theta+x_{\mathrm{sb}} \cos \left(\theta-\frac{2 \pi}{3}\right)+x_{\mathrm{sc}} \cos \left(\theta+\frac{2 \pi}{3}\right)\right\} \\
& x_{\mathrm{sq}}=-\sqrt{\frac{2}{3}}\left\{x_{\mathrm{sa}} \sin \theta+x_{\mathrm{sb}} \sin \left(\theta-\frac{2 \pi}{3}\right)+x_{\mathrm{sc}} \sin \left(\theta+\frac{2 \pi}{3}\right)\right\} \\
& x=v, i,
\end{aligned}
$$

where $\theta$ is the Park's transformation angle: $\theta=\omega \cdot t$.

\section{PROPOSED METHOD}

Fig. 3 shows the torque, direct and quadrature stator currents, and the mechanical speed obtained by simulation of a free-acceleration test at rated voltage on motors \#1 and \#2. All these data are labeled as 'exact' in contrast to the 'measured' or 'estimated' data in Fig. 4 to Fig. 6. The motors have been simulated with the double-cage model parameters in Table II, and with the catalogue rotor inertia of Table I. The instantaneous dq stator currents and mechanical speed in Fig. 3 are the data used for the parameters estimation method pro-
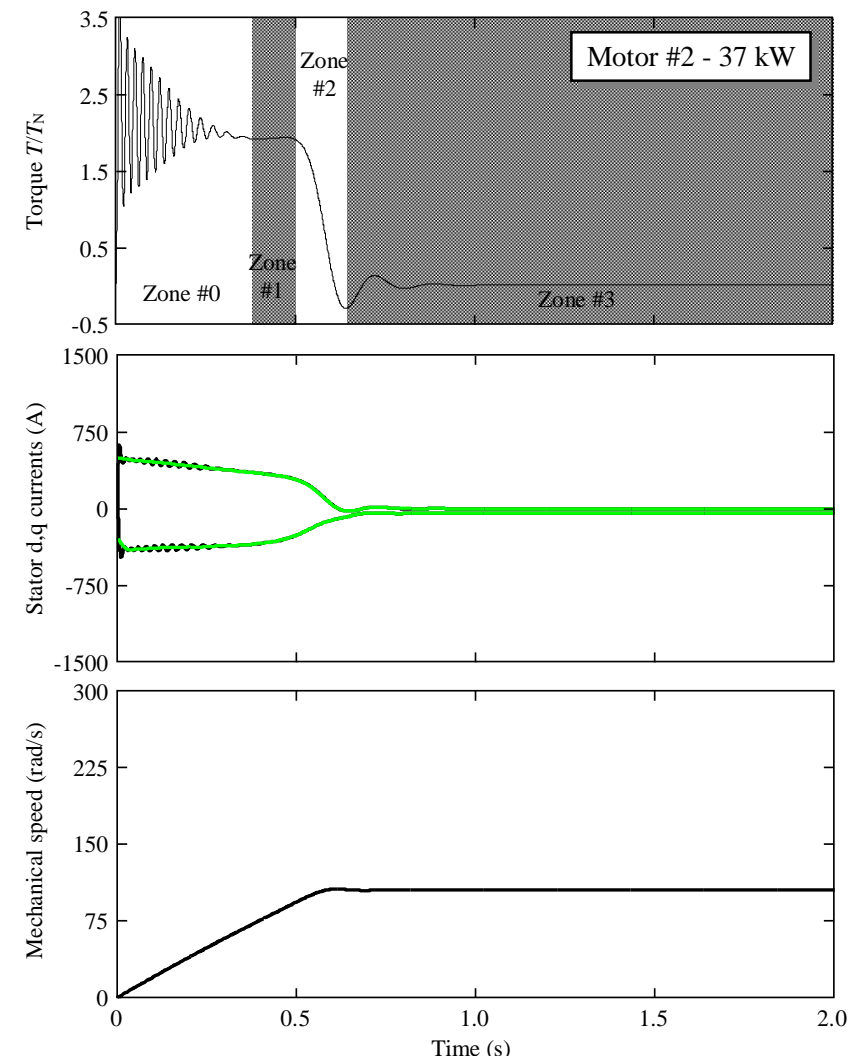
posed in this paper as will be shown in next subsections.

\section{A. Description and Justification of the Proposed Method}

The proposed estimation method estimates the steady-state machine impedance at specific slip points $s_{\mathrm{k}}$, i.e. estimates the values of $\underline{Z}_{\text {meas }}\left(s_{\mathrm{k}}\right)$ from the instantaneous data measured in a free-acceleration test, such as that in Fig. 3. Subsequently, the parameters of the double-cage model are estimated from the previous estimated steady-state machine impedances. The selection of the impedances is justified with the transient event in Fig. 3. The torque-time plot shows four data zones which correspond to different electromagnetic events.

Zone \#0 presents large oscillations due to the initial electromagnetic transient. Zone \#1 is the acceleration zone, where the instantaneous rms currents at any slip are similar to those of the steady-state currents at such slip. This is also the zone where the double-cage effect is more evident, i.e., large torques at large slips. Zone \#2 corresponds to the zone between the maximum torque point and the steady-state regime point near synchronism. Finally, Zone \#3 corresponds to the steady-state regime.

The instantaneous power method proposed in this paper evaluates the instantaneous active and reactive powers consumed by the motor from the measured voltages and currents as:

$$
\begin{gathered}
P(t)=\frac{1}{\mathrm{~T}} \int_{t-\mathrm{T} / 2}^{t+\mathrm{T} / 2} p(t) \mathrm{d} t=\frac{1}{\mathrm{~T}} \int_{t-\mathrm{T} / 2}^{t+\mathrm{T} / 2}\left(v_{\mathrm{a}} \cdot i_{\mathrm{a}}+v_{\mathrm{b}} \cdot i_{\mathrm{b}}+v_{\mathrm{c}} \cdot i_{\mathrm{c}}\right) \mathrm{d} t \\
I(t)=\sqrt{\frac{1}{T} \int_{t-\mathrm{T} / 2}^{t+\mathrm{T} / 2} \frac{\left(i_{\mathrm{a}}^{2}+i_{\mathrm{b}}^{2}+i_{\mathrm{c}}^{2}\right)}{3} \mathrm{~d} t} \\
U(t)=\sqrt{\frac{1}{\mathrm{~T}} \int_{t-\mathrm{T} / 2}^{t+\mathrm{T} / 2} \frac{\left(u_{\mathrm{a}}^{2}+u_{\mathrm{b}}^{2}+u_{\mathrm{c}}^{2}\right)}{3} \mathrm{~d} t} \\
S(t)=3 \cdot U(t) \cdot I(t) ; \quad Q(t)=\sqrt{S(t)^{2}-P(t)^{2}} .
\end{gathered}
$$

Let us define the instantaneous machine impedance, which is determined from the instantaneous measured active and reactive powers of (7) as:

$$
\underline{Z}(t)=\frac{3 U(t)^{2}}{P(t)-\mathrm{j} Q(t)} .
$$

The validity of the above instantaneous machine impedance is analyzed by estimation of the instantaneous torque as follows,

$$
T(t)=\frac{P(t)-3 R_{\mathrm{s}} I^{2}(t)}{\left(\omega_{\mathrm{s}} / \wp\right)} .
$$

Fig. 4a compares the estimated instantaneous torque from (9) with the exact dynamic torque. It can be observed that the estimated torque from (9) is a good indicator of the dynamic torque in zones \#1, \#2 and \#3, (where the instantaneous torque oscillations have vanished), while only can predict the average instantaneous torque in Zone \#0 because it is based on the averaged values in (7).

However, as the estimation method proposed in this paper is based on the steady-state impedance, it is not clear if the instantaneous impedance in (8) matches up with the steadystate impedance or not. In other words, if the instantaneous torque in (9) matches up with the steady-state torque. This comparison is made in Fig. 4b, where it can be observed the great similitude between both torques inside zones \#0 and \#1, despite small oscillations near zero speed. These small torque oscillations can be reduced if the active and reactive instantaneous power are previously smoothed [21], as shown in Fig. $4 c$. On the contrary, the instantaneous and the steady-state torque do not fit inside zones \#2 and \#3, as the maximum steady-state torque is greater than the maximum instantaneous torque (this phenomenon is always produced, as pointed out in [4]). As a consequence, the smoothed estimated torque from (9) is a good indicator of the steady-state torque only in zones \#0 and \#1 and, therefore, the smoothed instantaneous impedance from (8) can be a good approximation for the steady-state machine impedance in zones \#0 and \#1, where the double-cage effect is apparent.

A different method is required to estimate the (steady-state) machine impedance in zones \#2 and \#3, as the smoothed instantaneous impedance from (8) seems to be a bad indicator for such impedance. The results in Fig. 2 provide the solution: the torque predicted by the single- and double-cage models in zones \#2 and \#3 are very similar and exhibit a good agreement with that measured. Thus, the parameters of the single-cage model in zones \#2 and \#3 are calculated with the dynamic model based linear least square (LLSQ) method in [21] and, subsequently the machine impedance at specific slip points is evaluated from the estimated single-cage model.

In summary, the estimation procedure is composed by the following three steps. The first step (Section III.B) uses the data in zones \#0 and \#1 to evaluate the machine impedances at specific slip points. The method used in this step is called the instantaneous power method. The second step (Section III.C) uses the data in zones \#2 and \#3 to fit the parameters of a single-cage model by using the dynamic model based LLSQ algorithm in [21]. The machine impedance at specific slip points is evaluated from the estimated single-cage model parameters. In the third step (Section III.D), the parameters of a double-cage model able in all the slip range (from $s=0$ to $s=$ 1) are fit to the machine impedances calculated in the previous steps.

\section{B. Step 1: Estimation of the Machine Impedance in Zones \#0 and \#1 by the Instantaneous Power Method}

The machine impedance at specific slip points $s_{k}=s\left(t_{k}\right)$ is determined from the measured active and reactive power of (7) as:

$$
\underline{Z}_{k}\left(s_{k}\right)=\frac{3 U_{k}^{2}}{P\left(s_{k}\right)-\mathrm{j} Q\left(s_{k}\right)} .
$$



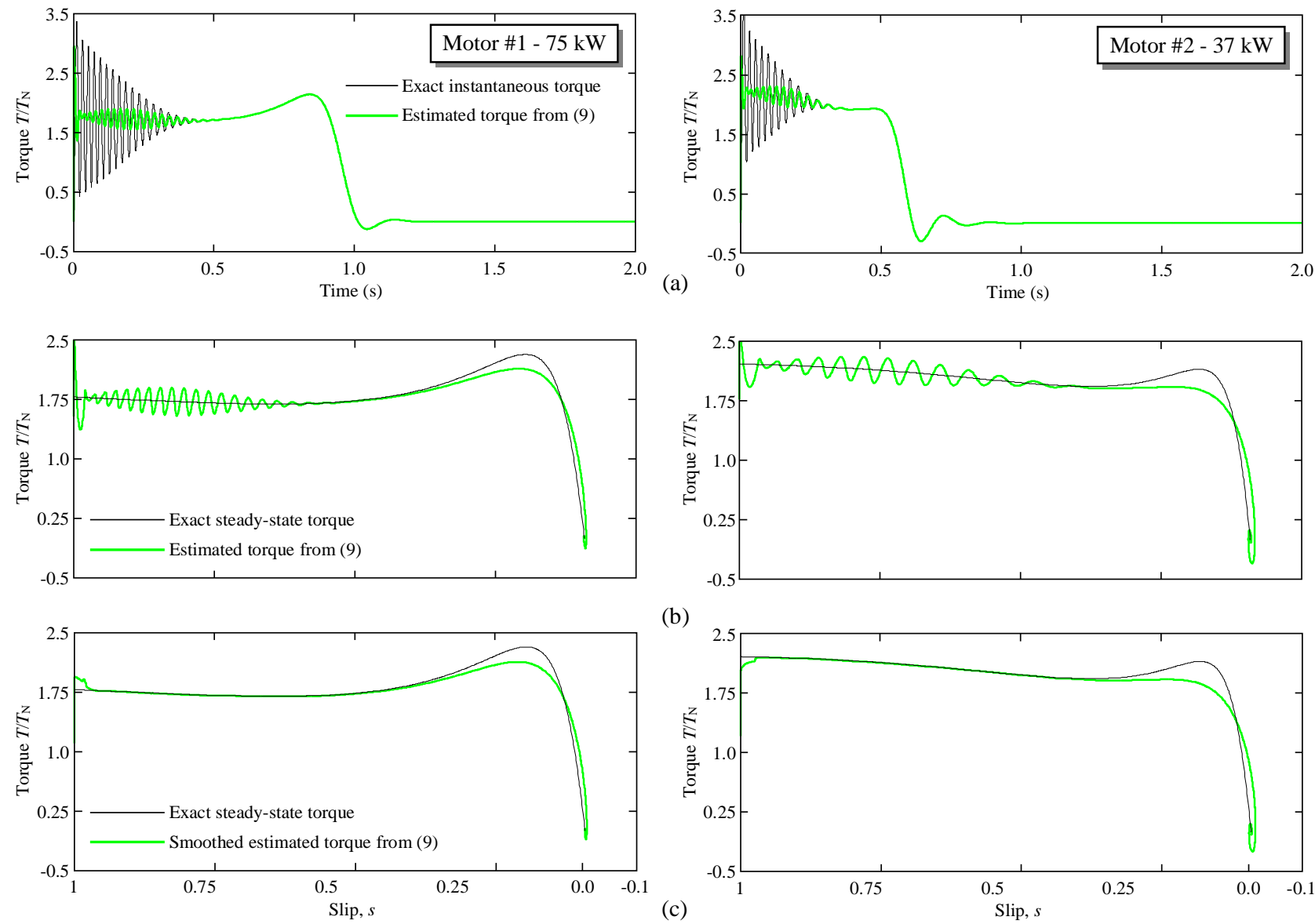

Fig. 4. (a) Exact (calculated by simulation) instantaneous and estimated torque, (b) exact (calculated by simulation) steady-state torque and estimated torque, and (c) exact (calculated by simulation) steady-state torque and smoothed estimated torque for motors \#1 and \#2.

It is worth noting that measured active and reactive power must be smoothed before being used in the above expression.

C. Step 2: Estimation of the Machine Impedance in Zones \#2 and \#3 by the dynamic model based LLSQ method in [21]

The main limitation in squirrel-cage induction motor parameters determination is the fact that the rotor currents are non-measurable. The single-cage model allows equations to be rewritten without using the rotor magnitudes [17]-[21]. It is worth noting that no similar deduction for the double-cage model has been found in the literature. For this reason, the double-cage model machine impedance is measured in the previous subsection in an indirect way by means of the instantaneous power method.

Ref. [21] uses an approximation of the rotor flux to improve the estimation procedure accuracy. This approach is used in the current paper and repeated here for clarity.

The elimination of the non-measurable rotor currents in (1) leads to the following set of linear equations:

$$
\left(\begin{array}{llllll}
a_{\mathrm{d} 1} & a_{\mathrm{d} 2} & a_{\mathrm{d} 3} & a_{\mathrm{d} 4} & a_{\mathrm{d} 5} & a_{\mathrm{d} 6} \\
a_{\mathrm{q} 1} & a_{\mathrm{q} 2} & a_{\mathrm{q} 3} & a_{\mathrm{q} 4} & a_{\mathrm{q} 5} & a_{\mathrm{q} 6}
\end{array}\right)\left(\begin{array}{c}
K_{1} \\
K_{2} \\
K_{31} \\
K_{32} \\
K_{4} \\
K_{5}
\end{array}\right)=\left(\begin{array}{l}
b_{\mathrm{d}} \\
b_{\mathrm{q}}
\end{array}\right),
$$

where

$$
\begin{gathered}
a_{\mathrm{d} 1}=\frac{\mathrm{d} i_{\mathrm{sd}}}{\mathrm{d} t} ; a_{\mathrm{d} 2}=i_{\mathrm{sd}} ; a_{\mathrm{d} 3}=-\left(\omega-\wp \omega_{\mathrm{mec}}\right) i_{\mathrm{sq}} ; a_{\mathrm{d} 4}=-\omega i_{\mathrm{sq}} \\
a_{\mathrm{d} 5}=-\left(\frac{\mathrm{d} v_{\mathrm{sd}}}{\mathrm{d} t}-\left(\omega-\wp \omega_{\mathrm{mec}}\right) v_{\mathrm{sq}}+\frac{1}{\omega} \frac{\mathrm{d} \wp \omega_{\mathrm{mec}}}{\mathrm{d} t} v_{\mathrm{sd}}\right) ; a_{\mathrm{d} 6}=-v_{\mathrm{sd}} \\
b_{\mathrm{d}}=-\frac{\mathrm{d}^{2} i_{\mathrm{sd}}}{\mathrm{d} t^{2}}+\left(2 \omega-\wp \omega_{\mathrm{mec}}\right) \frac{\mathrm{d} i_{\mathrm{sq}}}{\mathrm{d} t}+ \\
+\omega\left(\omega-\wp \omega_{\mathrm{mec}}\right) i_{\mathrm{sd}}-\frac{\mathrm{d} \wp \omega_{\mathrm{mec}}}{\mathrm{d} t} i_{\mathrm{sq}}
\end{gathered}
$$



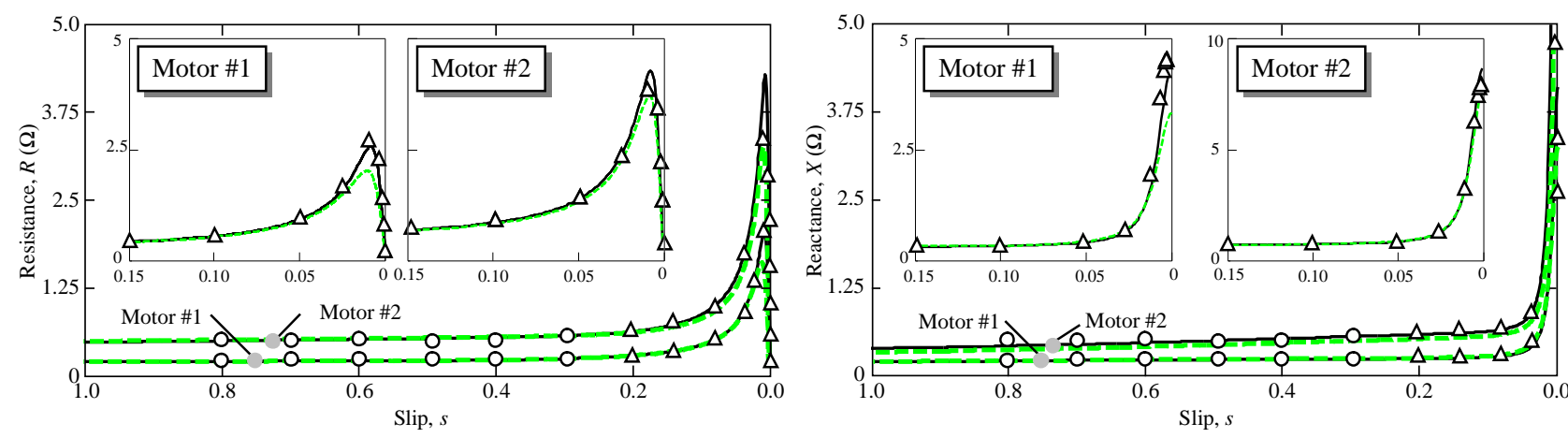

Exact (double-cage model of Table II)

$\Delta \quad$ Estimated in step 1 (16)

O Estimated in step 2 (22)

- - - - Parameters of Table III

Fig. 5. Exact (calculated by simulation) and estimated resistance- and reactance-slip curves for \#motor 1 and \#motor 2.

$$
\begin{gathered}
a_{\mathrm{q} 1}=\frac{\mathrm{d} i_{\mathrm{sq}}}{\mathrm{d} t} ; a_{\mathrm{q} 2}=i_{\mathrm{sq}} ; a_{\mathrm{q} 3}=\left(\omega-\wp \omega_{\mathrm{mec}}\right) i_{\mathrm{sd}} ; a_{\mathrm{q} 4}=\omega i_{\mathrm{sd}} \\
a_{\mathrm{q} 5}=-\left(\frac{\mathrm{d} v_{\mathrm{sq}}}{\mathrm{dt}}+\left(\omega-\wp \omega_{\mathrm{mec}}\right) v_{\mathrm{sd}}-\frac{1}{\omega} \frac{\mathrm{d} \wp \omega_{\mathrm{mec}}}{\mathrm{d} t} v_{\mathrm{sq}}\right) ; a_{\mathrm{q} 6}=-v_{\mathrm{sq}} \\
b_{\mathrm{q}}=-\frac{\mathrm{d}^{2} i_{\mathrm{sq}}}{\mathrm{d} t^{2}}-\left(2 \omega-\wp \omega_{\mathrm{mec}}\right) \frac{\mathrm{d} i_{\mathrm{sd}}}{\mathrm{d} t}+ \\
+\omega\left(\omega-\wp \omega_{\mathrm{mec}}\right) i_{\mathrm{sq}}+\frac{\mathrm{d} \wp \omega_{\mathrm{mec}}}{\mathrm{d} t} i_{\mathrm{sd}} .
\end{gathered}
$$

Use of $n$ data points leads to the following overdetermined linear system:

$$
\left(\begin{array}{cccccc}
a_{\mathrm{d} 1}^{1} & a_{\mathrm{d} 2}^{1} & a_{\mathrm{d} 3}^{1} & a_{\mathrm{d} 4}^{1} & a_{\mathrm{d} 5}^{1} & a_{\mathrm{d} 6}^{1} \\
a_{\mathrm{q} 1}^{1} & a_{\mathrm{q} 2}^{1} & a_{\mathrm{q} 3}^{1} & a_{\mathrm{q} 4}^{1} & a_{\mathrm{q} 5}^{1} & a_{\mathrm{q} 6}^{1} \\
a_{\mathrm{d} 1}^{2} & a_{\mathrm{d} 2}^{2} & a_{\mathrm{d} 3}^{2} & a_{\mathrm{d} 4}^{2} & a_{\mathrm{d} 5}^{2} & a_{\mathrm{d} 6}^{2} \\
a_{\mathrm{q} 1}^{2} & a_{\mathrm{q} 2}^{2} & a_{\mathrm{q} 3}^{2} & a_{\mathrm{q} 4}^{2} & a_{\mathrm{q} 5}^{2} & a_{\mathrm{q} 6}^{2} \\
\vdots & \vdots & \vdots & \vdots & \vdots & \vdots \\
a_{\mathrm{d} 1}^{n} & a_{\mathrm{d} 2}^{n} & a_{\mathrm{d} 3}^{n} & a_{\mathrm{d} 4}^{n} & a_{\mathrm{d} 5}^{n} & a_{\mathrm{d} 6}^{n} \\
a_{\mathrm{q} 1}^{n} & a_{\mathrm{q} 2}^{n} & a_{\mathrm{q} 3}^{n} & a_{\mathrm{q} 4}^{n} & a_{\mathrm{q} 5}^{n} & a_{\mathrm{q} 6}^{n}
\end{array}\right)\left(\begin{array}{c}
K_{1} \\
K_{2} \\
K_{31} \\
K_{32} \\
K_{4} \\
K_{5}
\end{array}\right)=\left(\begin{array}{c}
b_{\mathrm{d}}^{1} \\
b_{\mathrm{q}}^{1} \\
b_{\mathrm{d}}^{2} \\
b_{\mathrm{q}}^{2} \\
\vdots \\
b_{\mathrm{d}}^{n} \\
b_{\mathrm{q}}^{n}
\end{array}\right),
$$

which can be rewritten as

$$
\mathbf{A x}=\mathbf{b} .
$$

This overdetermined linear system is solved by the least square regression method

$$
\mathbf{x}=\left(\mathbf{A}^{\mathbf{t}} \mathbf{A}\right)^{-1} \mathbf{A}^{\mathbf{t}} \mathbf{b}
$$

where the estimated parameters are $\mathbf{x}=\left(K_{1}, K_{2}, K_{31}, K_{32}, K_{4}\right.$, $\left.K_{5}\right)$. The electrical parameters are calculated from the above parameters by considering the restriction $L_{\mathrm{sd}}=L_{\mathrm{rd}}[6]$ :

$$
\begin{aligned}
& L_{\mathrm{s}}=L_{\mathrm{r}}=\frac{K_{5}}{K_{32}} ; \quad \sigma=\frac{1}{K_{4} L_{\mathrm{s}}} \quad ; \quad M=\sqrt{(1-\sigma) L_{\mathrm{s}}^{2}} \\
& R_{\mathrm{s}}=L_{\mathrm{s}} \sigma K_{31} \quad ; \quad R_{\mathrm{r}}=L_{\mathrm{r}} \sigma K_{32} \quad ; \quad L_{\mathrm{sd}}=L_{\mathrm{rd}}=L_{\mathrm{s}}-M .
\end{aligned}
$$

The machine impedance at specific slip points $s_{\mathrm{k}}$ in the range between the maximum torque point and the synchro- nous speed are determined by using the single-cage model estimated parameters $\left(R_{\mathrm{s}}, R_{\mathrm{r}}, X_{\mathrm{sd}}, X_{\mathrm{rd}}, X_{\mathrm{m}}\right)$ as,

$$
\underline{Z}\left(s_{k}\right)=R_{\mathrm{s}}+\mathrm{j} X_{\mathrm{sd}}+\frac{1}{\frac{1}{\mathrm{j} X_{\mathrm{m}}}+\frac{1}{R_{\mathrm{r}} / s_{k}+\mathrm{j} X_{\mathrm{rd}}}} .
$$

\section{Step 3: Double-Cage Model Parameters Determination}

Two sets of machine impedances at different slips are estimated:

In this third step, the two sets of evaluated impedances in steps 1 and 2 are used to estimate the double-cage model parameters. This model has six unknown parameters, $R_{\mathrm{s}}, R_{\mathrm{r} 1}, R_{\mathrm{r} 2}, X_{\mathrm{sd}}, X_{1 \mathrm{~d}}, X_{2 \mathrm{~d}}, X_{\mathrm{m}}$, as it has been assumed that $X_{\mathrm{sd}}=X_{2 \mathrm{~d}}[6]$. The impedance at the slip point $s_{k}$ is

$$
\begin{gathered}
\underline{Z}\left(s_{k}\right)=R_{\mathrm{s}}+\mathrm{j} X_{\mathrm{sd}}+\frac{1}{\frac{1}{\mathrm{j} X_{\mathrm{m}}}+\frac{1}{R_{1} / s_{k}+\mathrm{j} X_{1 \mathrm{~d}}}+\frac{1}{R_{2} / s_{k}+\mathrm{j} X_{2 \mathrm{~d}}}} \\
\underline{Z}\left(s_{k}\right)=R\left(\mathbf{x}, s_{k}\right)+\mathrm{j} X\left(\mathbf{x}, s_{k}\right),
\end{gathered}
$$

where $\mathbf{x}=\left(R_{\mathrm{s}}, R_{1}, R_{2}, X_{\mathrm{sd}}, X_{\mathrm{m}}, X_{1 \mathrm{~d}}\right)$.

The parameters are estimated by solving the minimization problem

$$
\min \{F(\mathbf{x})\}=\min \left\{\sum_{k=1}^{N} w_{k}\left(\varepsilon_{\mathrm{R} k}^{2}\left(\mathbf{x}, s_{k}\right)+\varepsilon_{\mathrm{X} k}^{2}\left(\mathbf{x}, s_{k}\right)\right)\right\},
$$

where $N$ is the number of points, $w_{k}$ is the weight given to any point (all weights in this paper are given to unity), and the error functions are defined as

TABLE III

DOUBLE-CAGE MOdEl PARAMETERS IN PU ESTIMATED From THE FREE ACCELERATION TEST $\left(S_{\mathrm{B}}=P_{\mathrm{N}}, U_{\mathrm{B}}=U_{\mathrm{N}}, Z_{\mathrm{B}}=U_{\mathrm{B}}^{2} / S_{\mathrm{B}}\right)$

\begin{tabular}{ccccccc}
\hline \hline Motor & $r_{\mathrm{s}}$ & $x_{\mathrm{sd}}=x_{2 \mathrm{~d}}$ & $x_{\mathrm{m}}$ & $r_{1}$ & $x_{1 \mathrm{~d}}$ & $r_{2}$ \\
\hline$\# 1$ & 0.0548 & 0.0501 & 1.5011 & 0.0183 & 0.1119 & 0.1788 \\
\hline$\# 2$ & 0.0647 & 0.0394 & 1.6997 & 0.0161 & 0.1449 & 0.1030 \\
\hline$\# 3$ & 0.0363 & 0.0696 & 1.0781 & 0.0331 & 0.0812 & 0.2874 \\
\hline$\# 4$ & 0.0268 & 0.0562 & 1.1500 & 0.0254 & 0.0738 & 0.1698 \\
\hline$\# 5$ & 0.0359 & 0.0861 & 1.0202 & 0.0314 & 0.1149 & 0.1701 \\
\hline \hline
\end{tabular}



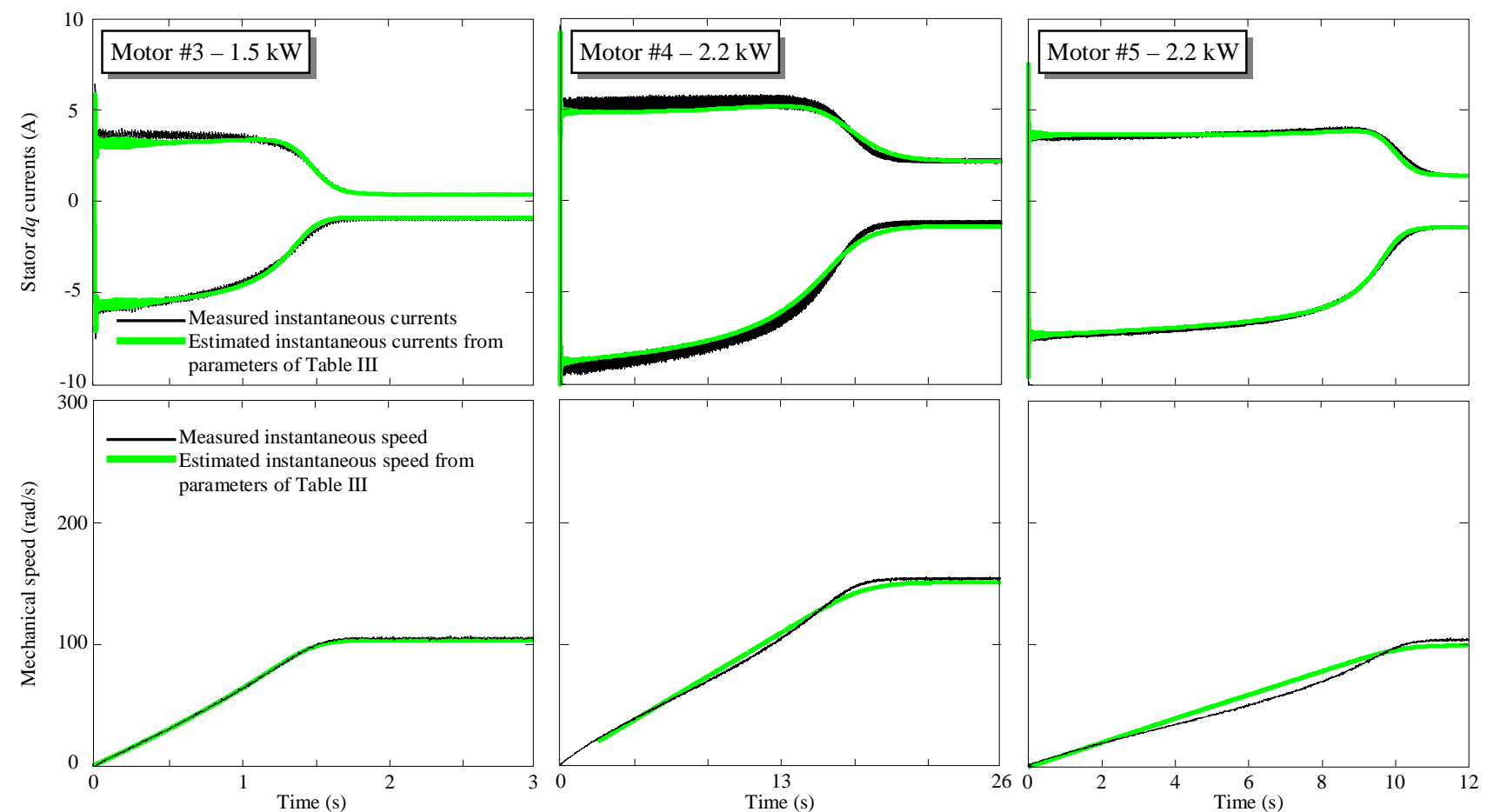

Fig. 6. Measured and estimated direct and quadrature stator currents and mechanical speed in a free acceleration test at reduced voltages on motors \#3, \#4 and \#5.

$$
\varepsilon_{\mathrm{R} k}=\frac{R_{\text {meas }}\left(s_{k}\right)-R\left(\mathbf{x}, s_{k}\right)}{R_{\text {meas }}\left(s_{k}\right)} ; \varepsilon_{\mathrm{X} k}=\frac{X_{\text {meas }}\left(s_{k}\right)-X\left(\mathbf{x}, s_{k}\right)}{X_{\text {meas }}\left(s_{k}\right)} .
$$

The Matlab routine Isqnonlin [30] is used in this paper to solve (22).

\section{E. Estimation Results Analysis}

Table III contains the parameters estimated using the freeacceleration test of motors \#1 and \#2. Fig. 2 shows the torque- and current-slip curves predicted with these parameters (discontinuous line). It can be observed that the results predicted by the proposed method exhibit a good agreement with the experimental measurements.

Fig. 5 compares the "exact" resistance and reactance values calculated with the double-cage model in Table II with those predicted in the step 1 (circles), in the step 2 (triangles) and by the double-cage model parameters of Table III.

\section{EXPERIMENTAL VALIDATION}

To validate the proposed method, motors \#3, \#4 and \#5 in Table I were tested in the laboratory at a reduced voltage in order to avoid leakage reactances saturation during the
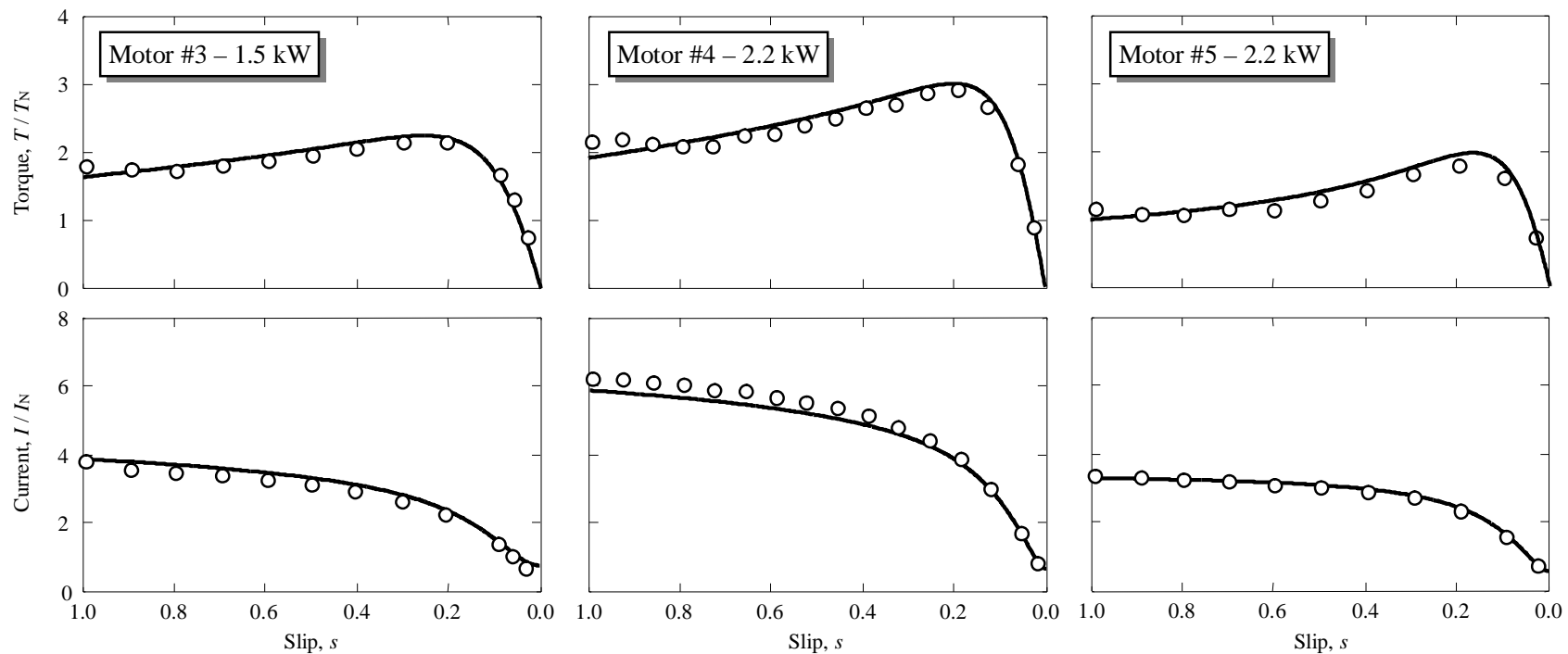

Fig. 7. Measured (marked with circles) and predicted (solid line) data torque- and current-slip curves for motors \#3, \#4 and \#5. Predicted curves have been obtained with the double-cage model estimated from a free acceleration test (Table III). 
steady-state and transient tests. The voltage used in all the tests was $0.52 U_{\mathrm{N}}$ for motor \#1, $0.24 U_{\mathrm{N}}$ for motor \#2 and $0.28 U_{\mathrm{N}}$ for motor \#3. These reduced voltages draw the rated current at zero speed. Fig. 6 shows the free acceleration test (at reduced voltage) of the three motors, whose measured data is used to calculate the double-cage model parameters in Table III.

Fig. 7 shows with circles the steady-state torque- and current-slip curves at rated voltage. Despite these measurements were taken at the mentioned reduced voltages, they have been subsequently prorated to rated values for comparison purposes:

$$
T_{\text {prorated }}=T_{\text {measured }}\left(\frac{U_{\mathrm{N}}}{U}\right)^{2} ; I_{\text {prorated }}=I_{\text {measured }}\left(\frac{U_{\mathrm{N}}}{U}\right),
$$

where $U_{\mathrm{N}}$ is the nominal value [31].

Fig. 7 also shows the estimated torque- and current-slip curves calculated with the parameters in Table III (solid lines). As can be seen, the agreement between the predicted and measured torque and current curves in the three motors is excellent.

\section{CONClusions}

This paper presents a new parameter estimation method for the double-cage model of squirrel-cage induction machines which uses the instantaneous stator voltages, currents and the mechanical speed in a free acceleration test. Firstly, the first set of machine impedances is calculated by the instantaneous power method, using the data in the range between the maximum torque point and the zero speed point (zones \#0 and $\# 1$ ). The second set of machine impedances is obtained from a single-cage dynamic model based on a LLSQ method, estimated with the data in the range between the maximum torque point and the steady-state speed point (zones \#2 and \#3). Lastly, the parameters of the double-cage model are fit to the estimated values of the machine impedances by a least square algorithm.

The method was tested in the laboratory with three motors. The steady-state torque- and current-slip curves predicted with the estimated parameters and those measured in the laboratory show an excellent agreement.

\section{ACKNOWLEDGMENTS}

The authors would like to thank A. Barrera and F. Quintana from ABB, S. A., Fábrica de Motores, for providing the experimental data of the Fig. 2 motors.

\section{REFERENCES}

[1] H. A. Toliyat, E. Levi, M. Raina, "A review of RFO induction parameter estimation techniques", IEEE Trans. Energy Conversion, Vol. 18, No.2, June 2003, pp. 271-283.

[2] IEEE Standard Test procedure for Polyphase Induction Motors and Generators, IEEE Std. 112-2004, Nov. 2004.
[3] IEC Rotating Eelectrical Machines-Part 28: Test methods for determining quantities of equivalent circuit diagrams for three-phase low-voltage cage induction motors, IEC 60034-28 Ed. 2.0 (2012-12)

[4] E. Laroche, M. Boutayeb, "Identification of the induction motor in sinusoidal mode", IEEE Trans. Energy Conversion, Vol. 25, No.1, March 2010, pp. 11-19.

[5] S. Ayasun, C. O. Nwankpa, "Induction motor test using MATLAB/Simulink and their integration into undergraduate electric machinery courses", IEEE Trans. Education, Vol. 48, No.1, Feb. 2005, pp. 37-46.

[6] F. Córcoles, J. Pedra, M. Salichs, L. Sainz, "Analysis of the induction machine parameter identification”, IEEE Trans. Energy Conversion, Vol. 17, No 2, June 2002, pp. 183-190.

[7] J. Pedra, F. Córcoles, "Estimation of induction motor double-cage model parameters from manufacturer data", IEEE Trans. Energy Conversion, Vol. 19, No 2, June 2004, pp. 310-317.

[8] J. Pedra, "On the determination of induction motor parameters from manufacturer data for electromagnetic transient programs" IEEE Trans. Power Systems, Vol. 23, No. 4, November 2008, pp. 1709-1718 .

[9] Power_AsynchronousMachineParams. The Mathworks Inc.: MATLAB Release 2012a, available at http://www.mathworks.com.

[10] I. Zubia, A. Zatarain, C. Alcalde, X. Ostolaza, "In situ electrical identification meted for induction wind generators", IET Electric Power Applications, Vol. 5, No. 7, 2011, pp. 549-557.

[11] M. O. Sonnaillon, G. Bisheimer, C. De Angelo, G. O. Garcia, "Automatic induction machine parameters measurements using standstill frequencydomain tests", IET Electric Power Applications, Vol. 1, No. 5, 2007, pp. 833-838.

[12] L. A. S. Ribeiro, C. B. Jacobina, A. M. N. Lima, A. C. Oliveira, "Realtime estimation of the electric parameters of an induction machine using sinusoidal PWM voltage waveforms", IEEE Trans. Industry Appl., Vol. 36, No. 3, 2000. pp. 743-754.

[13] C. B. Jacobina, J. E. C. Filho, A. M. N. Lima, "Estimating the parameters of induction machine at standstill", IEEE Trans. Energy Conversion, Vol. 17, No.1, March 2002, pp. 85-89.

[14] S. Jafarzadeh, C. Lascu, S. Fadali, "State estimation of induction motor drives using the unscented Kalman filter", IEEE Trans. Industrial Electronics, Vol. 59, 2012, pp. 4207-4216.

[15] A. Lalami, R. Wamkeue, I. Kamwa, M. Saad, J. J. Beaudoin, "Unscented Kalman filter for non-linear estimation of induction machine parameters", IET Electric Power Applications, Vol. 6, No. 9, 2012, pp. 611-620.

[16] E. Laroche, E. Sedda, C. Durieu, "Methodological insights for online estimation of induction motor parameters", IEEE Trans. Control Syst. Technol., Vol. 16, No. 5, Sept. 2008, pp. 1021-1028.

[17] J. Stephan, M. Bodson, J. Chiasson, "Real-time estimation of the parameters and fluxes of induction motors", IEEE Trans. Industry Appl., Vol. 30, 1994, pp. 746-758.

[18] M. Cirrincione, M. Pucci, G. Cirrincione, G. A. Capolino, "A new experimental application of least-squares techniques for the estimation of the induction motor parameters" IEEE Trans. Industry Appl., Vol. 39, 2003, pp. 1247-1256.

[19] M. Cirrincione, M. Pucci, G. Cirrincione, G. A. Capolino, "Constrained minimization for parameters estimation of induction motor in saturated and unsaturated conditions", IEEE Trans. Industrial Electronics, Vol. 52, 2005, pp. 1391-1402.

[20] M. Cirrincione, M. Pucci, "Identification of an induction motor with the least-squares method", Elect. Eng. Res. Rep., No. 10, Dec. 2000, pp. 2230 .

[21] H. Kojooyan-Jafari, Ll. Monjo, F. Córcoles, J. Pedra; "Parameter estimation of wound-rotor induction motors from transient measurements", IEEE Trans. Energy Conversion, Vol. 29, No.2, 2014, pp. 300-308.

[22] S. R. Shaw, S. B. Leeb, "Identification of induction motor parameters from transient stator current measurements", IEEE Trans. Industrial Electronics, Vol. 46, 1999, pp. 139-149.

[23] R. Wamkeue, D. Aguglia, M. Lakehal, P. Viarouge, "Two-step method for identification of nonlinear model of induction machine", IEEE Trans. Energy Conversion, Vol. 22, No.4, Dec. 2007, pp. 801-809.

[24] J. A. de Kock, F. S. van der Merwe, H. J. Vermeulen, "Induction motor parameter estimation through an output error technique", IEEE Trans. Energy Conversion, Vol. 9, No.1, March 1994, pp. 69-76.

[25] R. Wamkeue, I. Kamwa, M. Chacha, "Unbalanced transients-based maximum likelihood identification of induction machine parameters", IEEE Trans. Energy Conversion, Vol. 18, No.1, March 2003, pp. 33-40. 
[26] C. Grantham, D. J. McKinnon, "Rapid parameter determination for induction motor analysis and control", IEEE Trans. Industry Appl., Vol 39, No. 4, 2003, pp. 1014-1020.

[27] Whei-Min Lin, Tzu-Jung Su, Rong-Ching Wu, "Parameter identification of induction machine with a starting no-load low-voltage test", IEEE Trans. Industrial Electronics, Vol. 59, No. 1, Jan. 2012, pp. 352-360.

[28] J. Pedra, L. Candela, L. Sainz, "Modeling of squirrel-cage induction motors for electromagnetic transient", IET Electric Power Applications, Vol. 3, No. 2, March 2009, pp. 111-122.

[29] R. Babau, I. Boldea, T. J. E. Miller, N. Muntean, "Complete parameter identification of large induction machines from no-load accelerationdeceleration tests", IEEE Trans. Industrial Electronics, Vol. 54, No. 4, 2007, pp. 1962-1972.

[30] The MathWorks, Inc., Matlab 7.9 (2009b). Natick, MA: 2009.

[31] Ll. Monjo, F. Córcoles, J. Pedra, "Saturation effects on torque- and current-slip curves of squirrel-cage induction motors", IEEE Trans. Energy Conversion, Vol. 28, No. 1, 2013, pp. 243-254 